\title{
A simple method to improve the accuracy of non- invasive ultrasound in selecting TIA patients for cerebral angiography
}

\author{
P Humphrey, P Sandercock, J Slattery
}

\begin{abstract}
A prospective study is reported of the ability of $B$ mode ultrasound imaging and continuous wave Doppler flow studies to detect different degrees of stenosis of the extracranial internal carotid artery (ICA) in $\mathbf{1 8 6}$ arteries in 99 patients with transient ischaemic attacks (TIA) and minor ischaemic stroke. A simple mathematical equation has been developed which combines the image and flow data to provide a single predictor of the degree of angiographic stenosis which has advantages over either ultrasonic modality used alone. The sensitivity and specificity of the predictive model in the detection of stenosis $\geq 25 \%$ was $73 \%$ and $98 \%$, of stenosis $\geq 50 \%$ was $90 \%$ and $93 \%$, of stenosis $\geq 75 \%, 65 \%$ and $99 \%$ and occlusion $100 \%$ and $94 \%$ respectively. The principal clinical value of ultrasound screening is to spare patients with "non-significant" stenosis the risk of unnecessary angiography. Thus a simple measure of the Duplex screening tests' performance is the proportion of all strokes occurring as a complication of angiography that are avoided by changing the investigation policy from "angiograms for all carotid TIA and minor ischaemic stroke patients" to "angiograms for all patients with abnormal ultrasound results". If Duplex scanning were used to select patients most likely to have a significant abnormality on angiography, depending on the degree of stenosis to be detected, $52-85 \%$ of angiographic strokes might be avoided. If the predictive equation were used 62$88 \%$ of angiographic strokes might be avoided.
\end{abstract}

Walton Hospital, Rice Lane, Liverpool P Humphrey

Department of Clinical

Neurosciences, Western General Hospital, Edinburgh P Sandercock J Slattery

Correspondence to: Dr P Humphrey, Walton Hospital, Rice Lane, Kingdom.

Received 4 May 1989 and in revised form 18 December 1989. Accepted 16 January 1990 lesion of the internal carotid artery (personal data $a^{3} d^{34}$ ). In such patients the risks of stroke after cerebral arterial angiography varies between $1 \%$ and $5 \%, 5-7$ although the risk of permanent or disabling stroke is less (perhaps $0 \cdot 3-4 \cdot 74 \%)^{67}$

Thus in centres where most patients with TIA have cerebral angiography, many of the angiograms will not demonstrate a severe enough lesion to justify surgery (or randomisation in one of the current randomised controlled trials of carotid endarterectomy), and therefore a large number of patients will have been unnecessarily, as it turns out for them, exposed to the risks of angiography.

Carotid ultrasound studies are increasingly used to screen patients to select those most likely to have a surgical lesion. To remove the risk of angiography altogether, a proportion of patients in some centres are selected for surgery purely on the basis of non-invasive ultrasound. ${ }^{89}$

Ultrasound examination uses two principles: $B$ mode imaging to directly visualise the arterial wall and any local disease and Doppler flow studies to detect either the increased flow and turbulence associated with a tight stenosis or the absence of flow to suggest the vessel is occluded. The early reports of Doppler flow studies suggested that its sensitivity for stenoses less than $50 \%$ diameter reduction might be as low as $36 \%$. ${ }^{10}$

Recent studies using careful diagnostic criteria combined with spectral analysis have improved sensitivity for such lesions to $90^{11}$ $100 \%{ }^{12}$ and improved the sensitivity for mild disease (stenosis of $25 \%$ or greater) to between $77 \%^{11}$ and $99 \%,{ }^{12}$ yet maintaining specificity high at $90 \%{ }^{11}$ and $84 \%^{12}$ respectively. B-mode imaging achieves very high sensitivity $(70-100 \%)^{13-19}$ for mild disease, though sensitivity for severe stenosis is only, $60-70 \%{ }^{13-19}$ because calcification or fibrosis within the lesion tends to scatter the ultrasound beam making it difficult to visualise the dimensions of the remaining lumen accurately..$^{1517}$ In the diagnosis of occlusion, B mode imaging alone is notoriously unreliable, with sensitivity of $36-90 \% .^{14-19}$ The addition of Doppler flow studies can improve sensitivity to $100 \%{ }^{14}$, but the positive predictive value remains low at $53-86 \%{ }^{14-19}$ in other words, $14-37 \%$ of patients with occlusion (which is not surgically treatable) on ultrasound investigation prove to have a tight stenosis (which can be corrected surgically). For this reason Levien ${ }^{14}$ has advised that all patients with ultrasonographic features of 
occlusion should have angiography. Equally importantly, if the plaque is not echogenic the lumen may be severely narrowed, yet the $B$ mode image may appear relatively normal; it is only the Doppler flow study which then reveals the true situation, namely, a tight stenosis. 1121416

There are therefore several areas of difficulty in the use of ultrasound methods: B mode imaging performs best for the detection of mild to moderate disease, and Doppler flow studies are best at detecting moderate to severe disease. There is no widely used valid method to combine the data from the two types of study to produce a single estimate of diameter stenosis reliable at all levels of severity. If such a method were available, it would also be very useful in follow up studies of the progression of carotid atheroma from the mildest form to the eventual development of complete occlusion.

Thus we set out to develop and test such a method in a consecutive series of patients with carotid distribution TIA and minor stroke who were all destined to have angiography.

\section{Method}

PATIENTS

The study involved 100 patients referred to the Mersey Regional Neurosciences Unit who had had either a carotid TIA or minor ischaemic stroke and who were potential candidates for carotid endarterectomy. The decision to pursue angiography was made on clinical grounds before the ultrasonographic examination, to ensure that patients were not selected for angiography on the basis of their test results (such a policy would bias the assesssment of the tests' performance). ${ }^{20}$

\section{ULTRASOUND TECHNIQUE}

The ultrasound examinations were performed before angiography. The continuous wave (CW) Doppler peak systolic frequency shift was measured with A Kranzbuhler 4 and $8 \mathrm{MHz}$ probe system (the $8 \mathrm{MHz}$ probe for the supratrochlear artery). Using the $4 \mathrm{MHz}$ probe the common, external and internal carotid arteries were examined throughout their extracranial length as far as was technically possible, using a similar protocol to Trockel. ${ }^{10}$ The maximum Doppler peak systolic frequency shift was determined in each internal carotid artery, that is, the measurement was made at the point of maximum stenosis.

Images of the internal, external and common carotid arteries were recorded in transverse and longitudinal planes on video tape and still photographs using a Diasonics CV400 scanner with $10 \mathrm{MHz}$ Duplex probe. The dimensions of the common, external and internal carotid arteries were measured, using electronic calipers which can be placed on a frozen image of the vessel, at several extracranial sites. In this study, the greatest stenosis of the internal carotid artery above the bifurcation was the measurement used for analysis.

The degree of arterial narrowing was taken as the percentage diameter stenosis measured in the longitudinal section. All the examinations were performed by one of the authors ( $\mathrm{PH}$, PS). In most of the examinations, both authors were present, and measurements were agreed upon by both observers before being recorded. Some examinations were performed and recorded by $\mathrm{P} \mathrm{H}$. Inter-observer variation was therefore not an important problem.

\section{ULTRASONIC DIAGNOSTIC CRITERIA}

Ultrasonic criteria for diagnosis of occlusion of the ipsilateral internal carotid artery were the presence of at least three of the major criteria and preferably one of the two additional criteria.

MAJOR CRITERIA FOR ICA OCCLUSION

1) Reversal of supratrochlear flow on the same side.

2) Reduced common carotid flow the same side.

3) Absent ICA flow on continuous wave Doppler study.

4) Absent flow signal within the lumen of the internal carotid artery on duplex scanning of internal carotid.

\section{ADDITIONAL CRITERIA FOR ICA OCCLUSION}

1) Non pulsatile ICA filled with echogenic material on $B$ mode image.

a2) "To-and-fro" flow in internal carotid artery stump.

\section{ANGIOGRAPHY}

The arterial angiograms were performed under local anaesthetic using a Siemens digital subtraction unit (Angioskop Digitron 2). If the symptomatic artery was normal or occluded no further radiographs were taken. If the symptomatic side was abnormal, then the contralateral artery was examined. Anteroposterior and lateral views were obtained routinely; in some cases, additonal oblique views were taken.

Table 1 Ability of ultrasound to detect stenoses greater or equal to $25 \%$

\begin{tabular}{|c|c|c|c|c|c|}
\hline & \multicolumn{2}{|c|}{$\begin{array}{l}\text { B mode image alone }(n=168) \\
\text { Angiography }\end{array}$} & & \multicolumn{2}{|c|}{$\begin{array}{l}\text { Predictive model }(n=168) \\
\text { Angiography }\end{array}$} \\
\hline & $+v e(1)$ & $-v e$ & & $+(1)$ & - \\
\hline $\begin{array}{r}\text { B mode }+ \text { ve } \\
- \text { ve }\end{array}$ & $\begin{array}{l}68 \\
14\end{array}$ & $\begin{array}{l}13 \\
73\end{array}$ & $\begin{array}{r}\text { Predictive Model }+ \\
-\end{array}$ & $\begin{array}{l}60 \\
22\end{array}$ & $\begin{array}{r}2 \\
84\end{array}$ \\
\hline $\begin{array}{l}\text { Sensitivity } \\
\text { Specificity } \\
\text { Positive predictive value } \\
\text { Negative predictive value }\end{array}$ & \multicolumn{2}{|c|}{$\begin{array}{l}83 \% \\
85 \% \\
84 \% \\
84 \%\end{array}$} & & \multicolumn{2}{|c|}{$\begin{array}{l}73 \% \\
98 \% \\
97 \% \\
79 \%\end{array}$} \\
\hline
\end{tabular}
equal to $25 \%$ or less than $25 \%$ respectively.
endiograt 
Table 2 Ability of ultrasound to detect stenoses greater or equal to $50 \%$

\begin{tabular}{|c|c|c|c|c|c|}
\hline & \multicolumn{2}{|c|}{$\begin{array}{l}\text { B mode image alone }(n=168) \\
\text { Angiography }\end{array}$} & & \multicolumn{2}{|c|}{$\begin{array}{l}\text { Predictive model }(n=168) \\
\text { Angiography }\end{array}$} \\
\hline & $+v e$ & $-v e$ & & $+v e$ & $-v e$ \\
\hline $\begin{array}{r}\text { B mode }+ \text { ve } \\
- \text { ve }\end{array}$ & $\begin{array}{r}49 \\
3\end{array}$ & $\begin{array}{r}14 \\
102\end{array}$ & $\begin{array}{r}\text { Predictive Model }+ \\
-\end{array}$ & $\begin{array}{r}47 \\
5\end{array}$ & $\begin{array}{r}8 \\
108\end{array}$ \\
\hline $\begin{array}{l}\text { Sensitivity } \\
\text { Specificity } \\
\text { Positive predictive value } \\
\text { Negative predictive value }\end{array}$ & \multicolumn{2}{|c|}{$\begin{array}{l}94 \% \\
88 \% \\
92 \% \\
97 \%\end{array}$} & & \multicolumn{2}{|c|}{$\begin{array}{l}90 \% \\
93 \% \\
85 \% \\
96 \%\end{array}$} \\
\hline
\end{tabular}

Three radiologists, who were "blind" to the ultrasound findings, measured the internal carotid artery at its narrowest point above the bifurcation by estimating where the original arterial wall was thought to have been and then calculating the percentage stenosis based on the diameter reduction. The degree of narrowing was taken as the mean of the three radiologists' measurements.

\section{STATISTICAL METHODS}

Standard linear regression lines and correlation coefficients were calculated using the statistical program GLIM.$^{21}$ When assessing the performance of ultrasonography against the gold standard of angiography, sensitivity, specificity, positive and negative predictive value, likelihood ratios and receiver-operator curves were calculated by the standard method. ${ }^{20}$

Standard regression techniques were used to calculate an equation to predict the degree of stenosis likely to be found from an angiogram from values assessed by ultrasound image and the peak systolic Doppler shift.

Although the predictive equation is intended to provide an estimate of the stenosis which would be measured by an angiogram, the best criterion for deciding whether a patient has stenosis more than a given value is not necessarily whether the predictor is greater than this value. This will depend on the relative costs of the two possible types of error involvedclaiming stenosis greater than this value when in fact is is smaller or claiming stenosis less than this value when in fact it is higher.

Unfortunately, the cost is known only for the first type of error, this being the risk of a stroke due to an angiogram. Hence it is not possible to choose a decision criterion to minimise costs. Tables 1,2 and 3 use the value of the predictor which minimises the total number of wrong classifications.

\section{RISK OF ANGIOGRAPHY}

At the time this paper was first prepared, we assumed an angiographic stroke risk of $2 \%$.
Since then, Hankey et $a l^{22}$ have prepared a formal statistical overview of all the prospective studies of angiographic stroke risk in TIA and minor ischaemic stroke risk. They reported a risk of all strokes of $4 \cdot 1 \%(95 \%$ CI $3 \cdot 3-5 \cdot 5 \%)$ and of permanent strokes of $1.0 \%(0 \cdot 6-1 \cdot 5 \%)$. Thus our estimate is at the lower end of the range estimated by Hankey. ${ }^{22}$

\section{Results}

Ninety nine patients had angiography and ultrasonography-14 patients had only one artery examined at angiography, leaving 186 carotid arteries that had both a satisfactory ultrasound examination and arterial angiography.

Quantitative measurements of peak systolic frequency shift were not made in the first 18 arteries (before our plans for a mathematical predictive model were finalised), so flow data measurements were only available for 168 arteries (though qualitative assessments of flow in the categories normal, moderate stenosis, severe stenosis or occlusion were available in all 18). The predictive equation, derived by multiple linear regression techniques was:

Predicted stenosis $=$

$1.08+0.315 \times I-0.0698 \times S^{3}+1.185$ $\times S^{2}+62.01 \times Z$

where $I$ = estimate of diameter stenosis from duplex image (inm\%).

$S=$ peak systolic frequency shift on Doppler flow in $\mathrm{KHz}$.

$\mathrm{Z}=\mathrm{Z}$ is set to zero, unless Doppler flow is zero, in which case $Z=1$.

The linear correlation coefficient between the estimate of percentage diameter stenosis measured by the $B$ mode ultrasound image and the measurement on the arterial angiogram (mean of the three independent radiologists' measurements) was $0.88(\mathrm{p}<0.001)$. The linear correlation coefficient between the estimate of percentage diameter stenosis derived the predictive equation and the angiogram was $0.90(\mathrm{p}<0.001)$.

Table 3 Ability of ultrasound to detect stenoses greater or equal to $75 \%$

\begin{tabular}{|c|c|c|c|c|c|}
\hline & \multicolumn{2}{|c|}{$\begin{array}{l}B \text { mode alone ( } n=168 \text { ) } \\
\text { Angiography }\end{array}$} & & \multicolumn{2}{|c|}{$\begin{array}{l}\text { Predictive model }(n=168) \\
\text { Angiography }\end{array}$} \\
\hline & $+v e$ & $-v e$ & & $+v e$ & $-v e$ \\
\hline $\begin{array}{r}B \text { mode }+ \text { ve } \\
- \text { ve }\end{array}$ & $\begin{array}{l}23 \\
11\end{array}$ & $\begin{array}{r}2 \\
132\end{array}$ & Predictive Model + & $\begin{array}{l}22 \\
12\end{array}$ & $\begin{array}{r}1 \\
133\end{array}$ \\
\hline $\begin{array}{l}\text { Sensitivity } \\
\text { Specificity } \\
\text { Positive predictive value } \\
\text { Negative predictive value }\end{array}$ & \multicolumn{2}{|c|}{$\begin{array}{l}68 \% \\
99 \% \\
92 \% \\
92 \%\end{array}$} & & \multicolumn{2}{|c|}{$\begin{array}{l}65 \% \\
99 \% \\
96 \% \\
92 \%\end{array}$} \\
\hline
\end{tabular}


Table 4 Ability of duplex and flow measurements to detect internal carotid artery occlusion

\begin{tabular}{|c|c|c|c|}
\hline & & \multicolumn{2}{|c|}{ Angiography } \\
\hline & & $\begin{array}{l}\text { Artery } \\
\text { occluded }\end{array}$ & $\begin{array}{l}\text { Artery } \\
\text { patent }\end{array}$ \\
\hline Duplex & $\begin{array}{l}\text { Artery occluded } \\
\text { Artery patent }\end{array}$ & $\begin{array}{r}13 \\
0\end{array}$ & $\begin{array}{r}10 \\
145\end{array}$ \\
\hline \multicolumn{2}{|c|}{$\begin{array}{l}\text { Sensitivity } \\
\text { Specificity } \\
\text { Positive predictive value } \\
\text { Negative predictive value }\end{array}$} & \multicolumn{2}{|l|}{$\begin{array}{r}100 \% \\
94 \% \\
56 \% \\
100 \%\end{array}$} \\
\hline
\end{tabular}

Receiver operating characteristic (ROC) curves were plotted to compare the performance of the B mode image, the Doppler peak frequency shift and the combined predictive model in the detection of three different degrees of internal carotid artery stenosis $(25 \%, 50 \%$ and $75 \%)$ as determined by angiography; at each level of stenosis, the predictive model performed best. (Curves available on request.)

Tables 1,2 and 3 give the data on the performance of the $B$ mode image alone and the predictive model (image and flow data together) in the detection of different degrees of stenosis. With stenoses of less than $25 \%$, the estimate from the B mode image scanner was not infrequently (13 arteries) more severe than the angiogram which accounted for the relatively reduced specificity of $85 \%$ and positive predictive value of $84 \%$. For the detection of stenoses of $50 \%$ or greater, the sensitivity $(94 \%)$, specificity $(88 \%)$, positive predictive value $(92 \%)$ and negative predictive value $(97 \%)$ were higher. For stenoses of $75 \%$ or greater, the sensitivity of B mode imaging was lower $(68 \%)$ though specificity was higher (99\%).

Table 4 gives the performance of duplex and flow data in the detection of internal carotid artery occlusion. Although the sensitivity, specificity and negative predictive values are very high (over $90 \%$ ), there is a small number (10 arteries) in which the duplex scan and Doppler flow suggested the artery was occluded but the angiogram showed a tight stenosis.

The main value of non-invasive screening tests is to identify patients with normal arteries who can then be spared the $1-5 \%$ risk of stroke. associated with cerebral angiography (we have based our calculations on an estimated risk of
$2 \%$ ). Patients with ultrasonic features of occlusion should still have angiography, since a proportion will turn out to have patent arteries as described above. It is therefore of some interest to calculate the number of patients who would be spared angiography in different hypothetical institutions assuming a $2 \%$ stroke risk (table 5). In institution $A$ the policy is that all patients with stenoses $>25 \%$ are eligible for carotid endarterectomy (or randomisation in one of the current controlled clinical trials of the procedure), whereas the policy in institutions $B$ and $C$ is that only patients with stenoses of $50 \%$ and over and $75 \%$ and over respectively, are eligible for surgery (or randomisation). The number of angiographic strokes prevented by ultrasound screening is somewhat improved, at all levels of disease, by the use of the predictive model in all three types of disease.

\section{Discussion}

We wanted to determine whether ultrasound screening of patients with TIA and stroke was as accurate and reliable as had been suggested in previous studies in Europe and North America. ${ }^{10-18}$ Our results are indeed very comparable, and our first conclusion would be that physicians and neurologists in the United Kingdom who routinely perform cerebral angiography on patients with TIA and minor stroke should consider using Doppler flow studies and B mode imaging performed by operators of proven accuracy to identify the patients most likely to have abnormal angiograms, and to spare patients with normal or minimally diseased arteries the risk of "unnecessary" angiography. Both Doppler flow studies and B mode imaging fulfil the criteria for an ideal screening test: ${ }^{20}$ no risk to the patient, cheap and, above all, both high sensitivity and specificity to detect the disease in question. To test the validity of the screening procedure, it should be compared against a "gold standard" such as biopsy or post mortem. It should be applied uniformly to a well defined, unselected group of people, representative of the population the screening test would be applied to, and the results of the screening test should be determined and recorded "blind" to the knowledge of whether disease was present or absent.

Unfortunately, many of the previous studies of Doppler ultrasound have fallen short of this

\begin{tabular}{|c|c|c|c|c|c|c|c|}
\hline Institution & $\begin{array}{l}\text { Patients with stenosis } \\
\text { greater than or equal to } \\
\text { this would be referred } \\
\text { for surgery/randomised } \\
\text { in a trial }\end{array}$ & $\begin{array}{l}\text { Number who would } \\
\text { be spared } \\
\text { angiography because } \\
\text { ultrasound showed } \\
\text { stenosis less than } \\
\text { "surgical threshold" }\end{array}$ & & $\begin{array}{l}\text { Number of those } \\
\text { "spared" } \\
\text { angiography who in } \\
\text { fact had a "surgical" } \\
\text { lesion (false - ves) }\end{array}$ & $\begin{array}{l}\text { Number who had } \\
\text { unnecessary } \\
\text { angiograms (false } \\
+ \text { ves) }\end{array}$ & $\begin{array}{l}\text { Number of } \\
\text { "angiographic" } \\
\text { strokes avoided" }\end{array}$ & $\begin{array}{l}\% \text { of all } \\
\text { angiographic } \\
\text { strokes avoided }\end{array}$ \\
\hline A & $25 \%$ & $\begin{array}{l}\text { Duplex } \\
\text { Predictive Model }\end{array}$ & $\begin{array}{l}518 \\
631\end{array}$ & $\begin{array}{r}83 \\
131\end{array}$ & $\begin{array}{l}77 \\
12\end{array}$ & $\begin{array}{l}10 \cdot 5 \\
12 \cdot 5\end{array}$ & $\begin{array}{l}52 \cdot 5 \\
62 \cdot 5\end{array}$ \\
\hline B & $50 \%$ & Duplex & $\begin{array}{l}625 \\
673\end{array}$ & 18 & 83 & $\begin{array}{l}12 \cdot 5 \\
12.5\end{array}$ & $62 \cdot 5$ \\
\hline C & $75 \%$ & $\begin{array}{l}\text { Predictive Model } \\
\text { Duplex } \\
\text { Predictive Model }\end{array}$ & $\begin{array}{l}673 \\
851 \\
863\end{array}$ & $\begin{array}{l}30 \\
65 \\
71\end{array}$ & $\begin{array}{r}48 \\
12 \\
6\end{array}$ & $\begin{array}{l}13 \cdot 5 \\
17 \\
17 \cdot 5\end{array}$ & $\begin{array}{l}67 \cdot 5 \\
85 \\
87 \cdot 5\end{array}$ \\
\hline
\end{tabular}

1) These calculations are based on the prevalence of different degrees of stenosis in our series of patients and assume 1,000 patients referred for ultrasound screening.

2) The figures above are the results of duplex scanning if used alone, the figures below, if the predictive model is used.

3) Assuming a $2 \%$ angiographic stroke risk, that is, a total of 20 strokes would be expected. 
ideal: none of the European or North American studies have applied the test to a group of patients similar to the sort of patients likely to have cerebral angiography to detect carotid stenosis in a United Kingdom neurology unit, that is, the great majority have carotid distribution TIA or minor ischaemic stroke. All of the previous studies have applied the test to heterogeneous mixtures of patients with TIA, stroke, asymptomatic carotid bruit and nonlocalised non-specific symptoms such as dizziness. To reflect the test's usage in the United Kingdom, we applied the test only to patients with TIA and minor ischaemic stroke, clinically confined to the carotid distribution, in whom angiography was planned.

Secondly, all patients should have the "gold standard" test (angiography in this case) and the decision about angiography should not be influenced by the results of the screening test, otherwise the assessment of the accuracy of the test would be biased. ${ }^{20}$ In several studies, only selected patients had angiography, and the correlations were made retrospectively; in others, only patients with abnormal test results had angiography. This is a serious potential bias. In our study we used a consecutive, unselected group of patients in whom the decision about angiography was made before the results of Doppler studies and imaging were known and angiography was performed irrespective of the test results.

The agreement between the ultrasound and angiography is best when aiming to detect stenosis of $50 \%$ or greater. The receiver operator characteristic curve shows that B mode scanning performs better than Doppler flow data, and the predictive model performs better than either test separately. If Doppler flow data only are used, then a peak systolic Doppler shift of greater than or equal to $4 \mathrm{MHz}$ is the threshold which provides the best compromise between maximal sensitivity and maximal specificity to detect stenoses greater than or equal to $50 \%$. Similar data have been obtained by others. ${ }^{10-12}$ For more serious disease (stenosis of $75 \%$ or more) sensitivity is lower but specificity is higher.

In patients with suspected carotid occlusion, where the lumen appears filled with irregular atheroma on duplex scanning, sometimes it is difficult to differentiate on occlusion from a very tight stenosis using imaging criteria alone. ${ }^{14-19}$ This is clearly of great importance when trying to identify patients suitable for carotid endarterectomy, since endarterectomy is not feasible in patients with occluded arteries. This difficulty can be reduced by careful insonation of the artery with the CW Doppler flow probe to detect a high velocity jet (which may be the only sign that the artery is still patent). If this jet is detected, then one knows with confidence that the artery is not occluded. In spite of taking great care in our series in the diagnosis of occlusion there were still 10 arteries in which an CW Doppler study failed to detect a patent lumen and hence an incorrect diagnosis of carotid occlusion was made. Our policy, henceforth will be to perform angiography on all patients with ultrasound features of carotid occlusion in order not to miss those few "pseudo occlusions" who turn out to have very tight stenosis on angiography. It is interesting that similar difficulties in the diagnosis of occlusion have been reported with intravenous digital subtraction angiography (IVDSA). Pexman ${ }^{22}$ performed intra-arterial carotid angiography on seven patients thought to have internal carotid occlusions on IVDSA; four turned out to have very tight stenosis on intra-arterial angiography.

If a single screening test on its own is unreliable, then it may be advantageous to include a second screening test. ${ }^{20}$ Table 5 shows that mathematically combining B mode imaging data with Doppler data will, at most levels of disease, improve sensitivity and specificity. This approach is more systematic than all previous attempts to combine data from the two tests.

Many methods yield an estimate of stenosis within a certain range (for example " 50 $75 \%$ "). This may be adequate for clinical purposes, but is less than ideal for follow up studies to assess progression of carotid stenosis. Physicians assessing the progress of treatment for hypertension would not be happy with a sphygmomanometer which gave readings of " $80-100 \% " \mathrm{mmHg}$, so neurologists might perhaps reasonably demand greater accuracy of ultrasound screening, to yield a single figure (such as $55 \%$ ) when assessing the progress of carotid stenosis. To provide such a single measurement we therefore developed a mathematical equation using multiple regression techniques, which appears to make a modest improvement in the performance of the test, either by cancelling out opposing errors in the two techniques, or by some other means. However, the equation has only been tested on the data from which it was derived. It is also only able to predict within the range of values in the original data set. It must now be tested in an independently collected set of patient data, preferably containing larger numbers of patients, and with more extreme values to fully test its performance in everyday practice. This work is in progress. The usefulness of the equation in long-term follow up studies is also being evaluated.

Despite the preliminary nature of the equation, we felt it would be informative to make some estimates of the likely impact of ultrasound techniques on the avoidance of strokes related to cerebral angiography for ischaemic cerebrovascular disease. In making these calculations, we have naturally had to make assumptions about the risks of stroke associated with angiography, the distribution of disease severity, and that the predictive equation would perform as well on other sets of patient data as it does on the data from which it was derived. Since the value of carotid surgery is unproven, we cannot introduce a counterbalancing "loss" of strokes occurring in the few cases who had negative screening tests yet had carotid disease severe enough to have benefited from surgery. The advantage of screening would be less if the risk of angiography were 
lower. Some physicians advocate a policy of angiography for patients with carotid bruits which might be cheaper, but such a policy has a higher risk of false positives and false negatives ${ }^{22}$ and many patients without bruits have significant stenoses ${ }^{22}$ yet would not, under this policy, have an angiogram. Even a policy of angiography for patients with bruits or abnormal ultrasonography would lead to some unnecessary angiograms, since some patients with bruits turn out not to have carotid stenosis. $^{23}$

Our data suggest that the use of screening by ultrasonography would avoid a substantial proportion of angiographic strokes, with the degree of benefit depending on the threshold for referral for surgery (or randomisation in a trial of surgery).

The gain from our innovative method to combine flow and image data in a formal, structured way by the use of a mathematical equation, is modest and does not reach statistical significance. Further work is needed to confirm whether this interesting trend will be large enough to be clinically worthwhile. Nonetheless, enthusiasm for ultrasound screening has always to be tempered by realism. We consider that decisions about carotid surgery should always be based on the results of intra-arterial angiography. We would not recommend, as some authors have, ${ }^{910}$ that surgery can be undertaken solely on the results of Doppler sonography and B mode imaging.

We would like to thank Dr L G Brock, Dr N R Clitherow and Dr T Smith for reporting the angiograms; Professor Robin Roberts T Smith for reporting the angiograms; Professor Robin Roberts
and Dr R Prescott for help with the computing and statistical aspects of the study. Much of the analytical work was undertaken while one of the authors (PS) was a visiting Professor at the Department of Epidemiology and Biostatistics at the University of McMaster, Hamilton, Ontario, Canada. The ultrasonic equipment used in this research was purchased with a grant from the Medical Research Council, the Chest Heart and Stroke Association, and the Mersey Regional Health Authority.

1 North American Symptomatic Carotid Endarterectomy Study Group. Carotid Endarterectomy: Three Critical Evaluations. Stroke 1987;18:987-9.

2 UK-TIA study group. Variation in the use of angiography and carotid endarterectomy by neurologists in the UKTIA aspirin trial. Br Med J 1983;286:514-7.

3 Pessin MS, Duncan GW, Mohr JP, Poskanzer DC. Clinical and angiographic features of transient ischaemic attacks. N Eng J Med 1977;296:358-62.

4 Toole JF, Janeway R, Choi K, Cordell R, Davis C, Johnston F, Miller HS. Transient ischaemic attacks due to atherosclerosis. A prospective study of 160 patients. Arch Neurol 1975;32:5-12.

5 Earnest F, Forbes G, Sandok BA, Piepgras DG, Faust RJ, Ilstrup DM, Arndt LT. Complications of Cerebral Angiography: Prospective Assessment of Risk. $\mathrm{Am} J$ Neuroradiol 1983;4:1191-7.

6 Dion JE, Gater PC, Fox AJ, Barnett HJM, Blom RJ. Clinical Events following Neuroangiography: A Prospective Events following Neuroangiog
Study. Stroke 1987;18:997-1004.

7 Steiner TJ, McIvor J, Perkin GD, Greenhalgh R, Rose FC. Morbidity of arch angiography: prospective survey. In: Gorbidity of arch angiography: prospective survey. In: Greenhalgh R, Rose FC, ed. Progr

8 Sandmann W, Hennerici M, Nullen H, Aulich A, Knab K, Kremer K. Carotid artery surgery without angiography: Risk or progress? In: Greenhalgh R, Rose FC, ed. Progress in stroke research 2. London: Pitman, 1983:447-60.

9 Walsh J, Markowitz I, Kerstein Md. Carotid endarterectomy for amaurosis fugax without angiography. Am J Surg 1986;152:172-4.

10 Trockel U, Hennerici $M$, Aulich A, Sandmann W. The superiority of combined continuous wave Doppler examination over perioribital Doppler for the detection of extracranial carotid disease. J Neurol Neurosurg Psyextracranial carotid dised
chiatry $1984 ; 47: 43-50$.

11 Harward RS, Bernstein RF, Fronek A. Range-gated pulsed Doppler power frequency analysis for the diagnosis of carotid arterial occlusive disease. Stroke 1986;17:924-8.

12 Roederer G, Langlois Y, Chan AW, et al. Ultrasonic duplex scanning of extracranial arteries: improved accuracy using new features from the common carotid artery. $J$ Cardiovasc Ultrasonography 1982;1:373-80.

13 Hennerici M, Reifschneider G, Trockel U, Aulich A. Detection of early atherosclerotic lesions by duplex scanning of the carotid artery. J Clin Ultrasound 1984;12: ning of 64 .

14 Zweibel WJ, Austin CW, Sackett JF, Strother CM. Correlation of high-resolution B-mode and continuous-wave tion of high-resolution B-mode and continuous-wave Doppler sonography with arteriography in the
of carotid stenosis. Radiology 1983;149:523-32.

15 Comerota AJ, Cranley JJ, Katz L, et al. Real-time B-mode imaging. A three-year multicentre experience. J Vasc Surg 1984;1:84-95.

16 Jacobs NM, Grant EG, Schellinger D, Byrd CM, Richardson JD, Cohan SL. Duplex sonography: criteria for stenosis, accuracy and pitfalls. Radiology 1985;154: 385-91.

17 Wolverson MK, Heiberg E, Sundaram M, Tantanasirviogse $\mathrm{S}$, Shields J. Carotid atherosclerosis: High-resolution real-time sonography correlated with angiography. $A J R$ 1983;140:355-61.

18 Levien LJ, Voll CL, Lithgow-Jolly P, Fritz VU. The value of non-invasive investigation in the diagnosis of total of non-invasive investigation in the diagnosis of total
occlusion of the internal carotid artery. Stroke occlusion of

19 Ricotta J, Bryan FA, Bond G, et al. Multicentre validation study of real-time (B-mode) ultrasound, arteriography and pathologic examination. J Vasc Surg 1987;6:515-20.

20 Tugwell P, Haynes RB, Sackett D. Clinical epidemiology. $A$ science for clinical medicine. Toronto. Little, Brown and Co 1985.

21 Baker RJ, Nelder JA. The GLIM System Release 3: Generalised Linear Interactive Modelling. London: Royal Statistical Society 1978.

22 Hankey GJ, Warlow CP, Sellar RJ. Cerebral Angiography. What are the risks for patients with mild ischaemic cerebrovascular disease? Stroke 1990;21:209-22.

23 Ginsberg MD, Cebul RD. Non-invasive diagnosis of carotid artery disease. In: Harrison MJG, Dyken ML, eds. Cerebral vascular disease. London, Butterworths 1983:215-54. 